\title{
Economic stress and condescending treatment in childhood and adult self-rated health: results from a population study in Sweden
}

\author{
Fredrik Granström ${ }^{1,2}$, Hans-Georg Eriksson ${ }^{1}$ and Anu Molarius $3,4^{*}$
}

\begin{abstract}
Background: Even today, 12\% of the children in Sweden live in poverty and many children are exposed to adverse experiences, such as being bullied, which may have long-term consequences on public health. This study examined the associations between economic stress and condescending treatment in childhood and self-rated health (SRH) in adulthood.

Methods: The study is based on 26,706 persons who responded to a postal survey questionnaire sent to a random sample of men and women aged 25-84 years in 2012 (response rate 53\%). The associations between childhood circumstances and adult SRH were analysed by logistic regression, adjusting for sex, age, economic stress in adulthood, condescending treatment in adulthood, socioeconomic status and several other known material, behavioural and psychosocial risk factors.

Results: In total, 39\% of both men and women reported economic stress in their family during childhood. 36\% of the men and $41 \%$ of the women indicated that they had been treated in a condescending manner, e.g. in school or at home, during childhood. Both economic stress in childhood and condescending treatment in childhood were strongly associated with adult SRH. The associations attenuated, but were still statistically significant after adjustment for adulthood circumstances and other risk factors.

Conclusion: Economic stress in childhood and condescending treatment in childhood were associated with SRH in adulthood, both independently and through adulthood circumstances. The results underline the importance of taking into account both material and psychosocial circumstances over the whole life course when developing public health measures.
\end{abstract}

Keywords: Childhood adversities, Life course, Self-rated health, Population studies, Sweden

\section{Background}

Over the last few decades, the life course perspective, including the association between childhood circumstances and adult health, has been increasingly acknowledged as an important field of study [1, 2]. It has been suggested that social conditions accumulate from birth and onwards to build a base for the

\footnotetext{
* Correspondence: anu.molarius@regionvastmanland.se

${ }^{3}$ Competence Centre for Health, Region Västmanland, 72189 Västerås, Sweden

${ }^{4}$ Department of Public Health, Karlstad University, Karlstad, Sweden

Full list of author information is available at the end of the article
}

development of health during the remaining life span [3]. Thus, a child's social conditions have both immediate health effects and long-term health consequences [4]. The latter is explained by the fact that body organs and body systems are still under development, and therefore more susceptible to adaptation to the social conditions [5]. Furthermore, the long-term effects of childhood circumstances are amplified by four separate mechanisms operating in parallel: impact on physical and emotional health; the shaping of future lifestyle; impact on the cognitive development (and thus school results); and the forming of the social identity [1]. These 
mechanisms are operating through complex interactions between psychological, psychosocial, social and biological factors [3]. For example, psychological stress during childhood can cause permanent problems with controlling emotions, to connect with other people and with self-esteem. Childhood social environment is also associated with health behaviour, such as smoking and heavy alcohol use, in adulthood [6,7].

Material conditions in the family during childhood have been shown to influence adult health status in several ways. Adverse material conditions increase the risk of impaired mental well-being among the parents which, as a consequence, leads to poorer parental support for the child [8]. Furthermore, material deprivation can be related to poor diet or overcrowding, affecting sleep quality and homework environment [9]. In addition, parental socioeconomic status has been shown to be independently related to health behaviour in adulthood [10].

Previous studies have shown that economic hardship during childhood has an impact on health in adulthood, regardless of current economic conditions [11]. This has been reported for several health measures such as self-rated health (SRH) $[12,13]$ and mental disorders [14-16]. Similarly, associations between current economic difficulties and poor SRH $[12,13,17]$ as well as impaired mental health $[14,18]$ have been found.

Experiences of being condescendingly treated have been shown to be strongly associated with poor SRH and mental disorders $[17,19]$. The same is true for women and men who have been bullied in the workplace [20]. Condescending treatment can be seen as interpersonal discrimination which, according to social epidemiology, is a strong risk factor for poor health [21, 22]. To our knowledge there are no studies on condescending treatment during childhood and health in adulthood. However, related concepts such as childhood adversities have been investigated. For example, previous studies have shown that exposure to bullying at school is associated with poor adult SRH [23] and poor mental health in adulthood [15, 24, 25]. It also increases the risk of being exposed to bullying in the workplace as an adult, which in turn has adverse effects on health [26]. In addition, stressful relations with parents in childhood have been shown to be related to ill health among middle-aged men [27] and serious conflicts within the childhood family have been shown to be associated with poor SRH in young adulthood in women [23].

In $2013,12 \%$ of the children in Sweden lived in poverty, defined as living in families receiving social benefit or being below a certain level of disposable income (e.g. about $1800 \mathrm{EUR} / \mathrm{month}$ for families with two adults and two children) [28]. In addition, many children are exposed to adverse experiences, for instance being bullied [29]. It is therefore important to study the associations between childhood material and psychosocial circumstances and adult health. We are not aware of previous studies that have simultaneously investigated childhood material and psychosocial factors and adult health in Sweden. According to life course epidemiology, material and psychosocial adversities in childhood increase the risk of corresponding adversities in adulthood [9]. Furthermore, adult lifestyle and social identity are shown to partly originate from childhood conditions $[1,6,7,10]$. Adult socioeconomic status such as educational level or employment status are other possible mediating factors [23]. Thus, taking into account these possible mediating and confounding factors is necessary to elucidate the association between childhood circumstances and adult health.

The aim of this study was to examine the associations between economic stress and condescending treatment in childhood and SRH in adulthood, both independently and through adulthood circumstances, in the general adult population in Sweden.

\section{Methods}

This study is based on a postal questionnaire (the Swedish National Public Health Survey) sent to a random population sample in Sweden in 2012. In four counties in the central part of Sweden, covering $39 \mathrm{mu}$ nicipalities with about one million inhabitants, extended population samples were drawn, stratified by gender, age group and municipality. In these counties the questionnaire included several additional questions, including questions on childhood circumstances (see Additional file 1). The sampling frame was the population register at Statistics Sweden, the statistical administrative authority in Sweden, covering all inhabitants of the study area. The survey was coordinated by the National Institute of Public Health, now The Public Health Agency of Sweden. Data collection was discontinued after two postal reminders. A total of 26,706 men and women aged 25-84 years were included in the study. The overall response rate was $53 \%$.

\section{Outcome}

SRH was assessed by the question "How do you rate your general health?" with the options "very good", "good", "fair", "poor" and "very poor". In the analyses, the categories "very good" and "good" were combined as well as the categories "poor" and "very poor" to avoid categories with small number of subjects.

\section{Childhood circumstances}

Economic stress in childhood was measured by the question "Did your family experience any economic difficulties when you grew up?" with the answer options "no", "yes, during minor part of childhood", "yes, during 
major part of childhood" and "yes, during the entire childhood". Condescending treatment in childhood was assessed by the question "Were you treated in a condescending manner while you were growing up, for example in school or at home?". The answer categories were "no", "yes, sometimes" and "yes, often".

\section{Adulthood circumstances}

Economic stress in adulthood was measured by a survey question on difficulty with covering expenses for food, rent, bills etc. during the past 12 months, with the answer options "no", "yes, once", "yes, several times". Condescending treatment in adulthood was assessed by the question "Have you during the past three months at any time experienced that you have been treated in a condescending manner by anyone?". The answer categories were "no", "yes, occasionally", and "yes, several times".

\section{Sociodemographic factors}

Information on sex, age, educational level and country of birth were obtained from official registers. Educational level was categorized into three levels: low (elementary school), medium (upper secondary school), and high (at least 3 years of university or corresponding education). Country of birth was categorized into born in Sweden, born in another Nordic country, born in another European country and born outside of Europe. Employment status was derived from a survey question about whether the respondent was employed, selfemployed, a student, unemployed, on sickness leave, on disability pension or retired.

\section{Psychosocial factors}

Social support was assessed by the question: "Can you get help from any person or persons if you have practical problems or are ill? E.g. get advice, borrow things, help with shopping, repairs etc.". The response options were: "Yes, always", "Yes, mostly", "No, mostly not" and "No, never". Burdensome domestic work was measured by a question on how often the respondent experienced domestic work as a burden ("all or most of the time", "sometimes", "seldom", "never").

\section{Behavioural factors}

The level of physical activity was measured with the question: "How much physical movement and exertion have you had in the last 12 months?", with the options: "Sedentary leisure time ( $<2 \mathrm{~h}$ a week)", "Moderate exercise in leisure time ( $\geqslant 2 \mathrm{~h}$ a week)", "Moderate, regular exercise in leisure time (sweat-inducing exercise at least for 30 minutes at a time 1-2 times a week)" and "Regular exercise and training (at least three times a week)". Daily smoking was measured by the question "Do you smoke daily?" (yes/no). Risk consumption of alcohol was measured by an index of three question (AUDIT-C) developed to identify "persons with hazardous and harmful patterns of alcohol consumption" [30]. The cut-offs for risk consumption in this study were 6 points or more for women and 8 points or more for men [31].

The individuals in the survey were informed that completed questionnaires would be linked to the Swedish official registries through the personal identification numbers, in order to access information on sex, age, geographic area, educational level and country of birth. Thus, the respondents gave their informed consent to the linking of registry data. Immediately after record linkage, the personal identification numbers were deleted. Statistics Sweden carried out the sampling and data collection and linkage with registry data, and delivered the de-identified data to the county councils. The survey was approved by the Regional Board of Ethics, Uppsala (EPN 2012/256).

\section{Statistical analyses}

Crude proportions reporting childhood economic stress and condescending treatment in childhood were calculated by sex, age, educational level, country of birth, employment status, current economic stress, current condescending treatment and other covariates. Differences in proportions were tested with chi-squared statistics. Also, distributions of SRH were calculated by sex, age, childhood economic stress and condescending treatment in childhood. To take into account circumstances in adulthood and other risk factors for SRH, multivariate analyses were carried out using multinomial logistic regression. The results are reported as odds ratios (OR) and $95 \%$ confidence intervals $(95 \% \mathrm{CI})$ for having poor and fair SRH, compared to good SRH. Since there was a moderate correlation (Spearman's rho $=0.31$ ) between childhood economic stress and condescending treatment in childhood these variables were added simultaneously in all models. In the first model, ORs for childhood economic stress and condescending treatment in childhood were adjusted for sex and age. In the second model, the ORs were adjusted for economic stress and condescending treatment in adulthood. In the third model, further adjustment was made for educational level, employment status, country of birth, social support, burdensome domestic work, smoking, high-risk alcohol consumption, and physical activity.

\section{Results}

In total, 39\% of both men and women reported economic stress in their family at least during some part of their childhood (Table 1). Similar proportions, 36\% of the men and $41 \%$ of the women, indicated that they had been treated in a condescending manner sometimes or often, e.g. in school or at home, during childhood. 
Table 1 Crude distribution (\%) of economic stress in childhood and condescending treatment in childhood by sex, educational level, country of birth, employment, current condescending treatment, current economic stress, social support, burdensome domestic work, daily smoking, risk consumption of alcohol and physical activity, 25-84 years

\begin{tabular}{|c|c|c|c|c|c|c|c|c|c|c|}
\hline & \multirow[b]{2}{*}{ N } & \multicolumn{5}{|c|}{ Economic stress in childhood } & \multicolumn{4}{|c|}{ Condescending treatment in childhood } \\
\hline & & Entire childhood & Major part & Minor part & No & $p$-value ${ }^{*}$ & Yes, often & Yes, sometimes & No & $p$-value* \\
\hline$\overline{\text { Total }}$ & 26,706 & 6.8 & 11.8 & 20.0 & 61.4 & & 7.7 & 31.1 & 61.2 & \\
\hline Sex & & & & & & $<.001$ & & & & $<.001$ \\
\hline Men & 12,221 & 6.2 & 11.5 & 21.1 & 61.3 & & 6.1 & 30.4 & 63.5 & \\
\hline Women & 14,485 & 7.4 & 12.0 & 19.1 & 61.4 & & 9.1 & 31.6 & 59.3 & \\
\hline Educational level & & & & & & $<.001$ & & & & $<.001$ \\
\hline Compulsory & 5617 & 9.8 & 14.7 & 19.6 & 55.9 & & 7.2 & 27.2 & 65.6 & \\
\hline Secondary & 11,863 & 6.9 & 11.9 & 20.2 & 61.0 & & 8.4 & 31.7 & 60.0 & \\
\hline Post-secondary & 9097 & 4.8 & 9.9 & 19.9 & 65.4 & & 7.1 & 32.7 & 60.2 & \\
\hline Country of birth & & & & & & $<.001$ & & & & $<.001$ \\
\hline Sweden & 23,078 & 5.6 & 10.9 & 19.1 & 64.4 & & 7.5 & 30.9 & 61.7 & \\
\hline Other Nordic country & 1593 & 14.5 & 18.0 & 23.7 & 43.9 & & 10.5 & 33.1 & 56.4 & \\
\hline Outside Nordic countries & 2035 & 14.4 & 17.6 & 27.1 & 40.9 & & 8.3 & 32.0 & 59.7 & \\
\hline Employment & & & & & & $<.001$ & & & & $<.001$ \\
\hline Employed & 12,271 & 5.0 & 10.5 & 20.2 & 64.3 & & 8.0 & 34.1 & 58.0 & \\
\hline Self-employed & 1668 & 5.0 & 10.6 & 18.7 & 65.7 & & 6.8 & 30.9 & 62.3 & \\
\hline Student & 500 & 9.4 & 12.6 & 24.6 & 53.4 & & 14.1 & 37.2 & 48.7 & \\
\hline Unemployed & 722 & 11.9 & 13.0 & 22.6 & 52.5 & & 17.5 & 36.6 & 45.9 & \\
\hline On sickness leave & 621 & 7.6 & 14.2 & 21.3 & 57.0 & & 13.8 & 32.5 & 53.6 & \\
\hline On disability pension & 813 & 14.3 & 16.4 & 20.5 & 48.8 & & 23.2 & 34.1 & 42.7 & \\
\hline Retired & 8667 & 7.9 & 12.7 & 19.8 & 59.6 & & 4.4 & 25.7 & 69.8 & \\
\hline Condescently treated during the & ast 3 mon & ths & & & & $<.001$ & & & & $<.001$ \\
\hline Yes, several times & 883 & 15.2 & 16.5 & 20.7 & 47.6 & & 34.7 & 36.5 & 28.8 & \\
\hline Yes, occasionally & 6246 & 8.6 & 14.3 & 22.2 & 54.9 & & 14.0 & 43.9 & 42.1 & \\
\hline No & 19,497 & 5.9 & 10.8 & 19.2 & 64.1 & & 4.4 & 26.7 & 68.8 & \\
\hline Economic stress past 12 months & & & & & & $<.001$ & & & & $<.001$ \\
\hline Yes, several times & 1888 & 16.8 & 20.4 & 22.1 & 40.7 & & 23.1 & 38.6 & 38.4 & \\
\hline Yes, once & 1317 & 10.7 & 14.6 & 24.4 & 50.3 & & 12.8 & 38.0 & 49.2 & \\
\hline No & 23,330 & 5.8 & 10.9 & 19.6 & 63.7 & & 6.2 & 30.1 & 63.8 & \\
\hline Social support & & & & & & $<.001$ & & & & $<.001$ \\
\hline No, never & 459 & 18.5 & 13.3 & 20.3 & 47.9 & & 20.8 & 31.3 & 47.9 & \\
\hline No, mostly not & 912 & 14.1 & 19.5 & 24.1 & 42.2 & & 18.4 & 38.8 & 42.8 & \\
\hline Yes, mostly & 7095 & 8.1 & 15.0 & 23.1 & 53.7 & & 9.9 & 36.9 & 53.2 & \\
\hline Yes, always & 18,004 & 5.6 & 10.2 & 18.6 & 65.6 & & 6.0 & 28.5 & 65.5 & \\
\hline Burdensome domestic work & & & & & & $<.001$ & & & & $<.001$ \\
\hline All or most of the time & 1857 & 14.5 & 16.3 & 19.1 & 50.1 & & 21.6 & 34.1 & 44.3 & \\
\hline Never/seldom/sometimes & 24,508 & 6.2 & 11.5 & 20.1 & 62.2 & & 6.7 & 30.9 & 62.4 & \\
\hline Daily smoker & & & & & & $<.001$ & & & & $<.001$ \\
\hline Yes & 3146 & 9.8 & 14.8 & 21.2 & 54.2 & & 11.8 & 31.5 & 56.6 & \\
\hline No & 23,346 & 6.4 & 11.4 & 19.8 & 62.4 & & 7.2 & 31.0 & 61.8 & \\
\hline Risk consumption of alcohol & & & & & & .002 & & & & $<.001$ \\
\hline Yes & 1166 & 8.2 & 14.2 & 21.0 & 56.6 & & 13.0 & 34.6 & 52.5 & \\
\hline No & 24,465 & 6.7 & 11.6 & 20.0 & 61.7 & & 7.5 & 31.0 & 61.5 & \\
\hline
\end{tabular}


Table 1 Crude distribution (\%) of economic stress in childhood and condescending treatment in childhood by sex, educational level, country of birth, employment, current condescending treatment, current economic stress, social support, burdensome domestic work, daily smoking, risk consumption of alcohol and physical activity, 25-84 years (Continued)

\begin{tabular}{lllllllll}
\hline Physical activity & & & & & $<.001$ & & \\
Sedentary & 3335 & 11.0 & 14.5 & 19.2 & 55.3 & 10.7 & 30.8 & 58.5 \\
Moderate & 12,655 & 6.5 & 11.9 & 20.2 & 61.5 & 7.2 & 30.6 & 62.2 \\
Moderate regular & 5906 & 5.8 & 11.2 & 20.4 & 62.7 & 6.9 & 32.0 & 61.1 \\
Regular exercise & 4438 & 5.8 & 10.2 & 19.3 & 64.7 & 7.6 & 31.7 & 60.7 \\
\hline
\end{tabular}

${ }^{*} p$-value based on chi-squared test

Economic stress during childhood was more common among persons with low educational level, those born outside Sweden, the unemployed and those on disability pension. Condescending treatment in childhood was most common among the unemployed and those on disability pension. Differences in the prevalence of childhood conditions were also found by adulthood circumstances and the behavioural and psychosocial risk factors included in the analyses.

When different age groups were compared, the proportions reporting economic stress during childhood were similar (Fig. 1). However, the proportion that reported that they were condescendingly treated in childhood was largest in the youngest age groups and smallest among the elderly.

In total, $68 \%$ of the respondents reported good SRH. The proportions with good SRH decreased by the frequency of exposure to economic stress and condescending treatment in childhood (Table 2). Only $50 \%$ of the respondents who reported economic stress during the entire childhood had good SRH in adulthood. Similarly, only $51 \%$ of those often exposed to condescending treatment in childhood had good SRH.
The results of the sex- and age-adjusted logistic regression analyses show that both economic stress in childhood and condescending treatment in childhood were strongly associated with poor SRH in adulthood (Table 3). Respondents reporting economic stress during the entire childhood (OR $=2.30,95 \% \mathrm{CI}: 2.29-3.25)$ or the major part $(\mathrm{OR}=1.83,95 \% \mathrm{CI}: 1.57-2.13)$ had increased risk of poor SRH in adulthood. Similarly, respondents reporting that they were exposed to condescending treatment during childhood had increased risk, especially those who reported that they often were condescendingly treated $(\mathrm{OR}=4.20,95 \%$ CI:3.57-4.94). The associations were considerably attenuated, but still statistically significant [OR $=2.17$ (95\% CI:1.81-2.59) for economic stress during the entire childhood, OR $=1.59$ (95\% CI:1.36-1.87) for major part of the childhood and OR $=2.60$ (95\% CI:2.18-3.10) for having often been condescendingly treated in childhood], when adjusted for adulthood circumstances. Current economic stress and condescending treatment had stronger associations with poor SRH than childhood conditions. After adjustment for socioeconomic status, psychosocial and behavioural risk factors, the associations

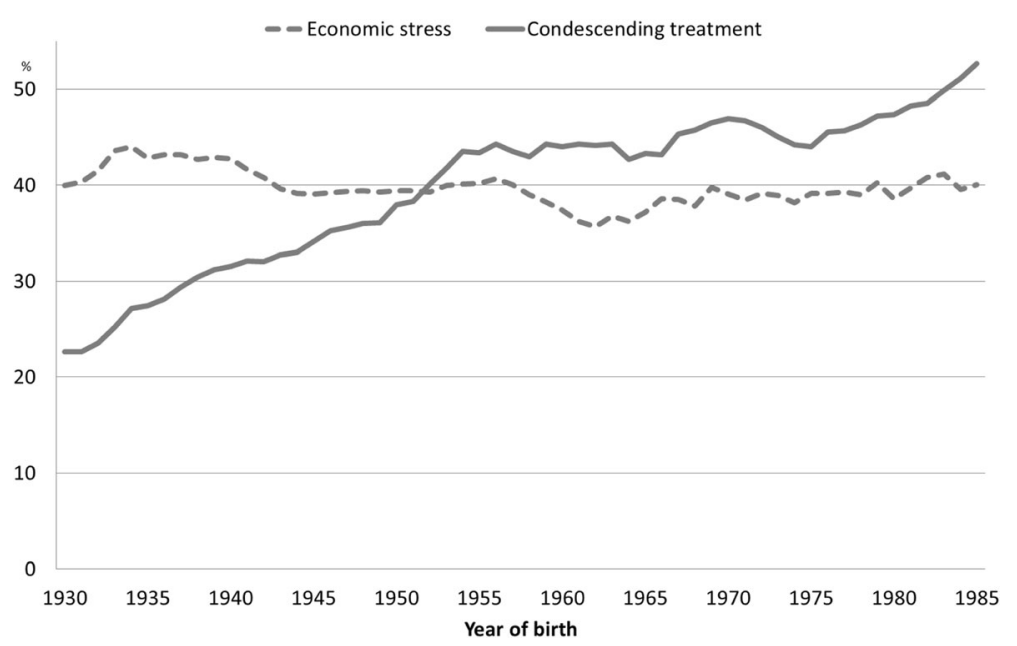

Fig. 1 Proportions reporting economic stress in childhood and condescending treatment in childhood by year of birth 
Table 2 Crude distribution (\%) of self-rated health by sex, age, economic stress in childhood and condescending treatment in childhood

\begin{tabular}{lllllll}
\hline & $N$ & Poor & Fair & Good & $p$-value* \\
\hline Total & 25,951 & 6.2 & 26.2 & 67.6 & \\
Sex & & & & & $<.001$ \\
$\quad$ Men & 11,893 & 5.4 & 25.8 & 68.8 & \\
Women & 14,058 & 6.9 & 26.5 & 66.6 & \\
Age & & & & & $<.001$ \\
25-34 & 2555 & 3.7 & 14.0 & 82.3 & \\
35-49 & 5700 & 5.6 & 18.8 & 75.6 & \\
50-64 & 7499 & 7.4 & 24.9 & 67.7 & \\
65-84 & 10,197 & 6.4 & 34.4 & 59.4 & \\
Economic stress in childhood & & & & & $<.001$ \\
svårigheter under uppväxten & & & & & \\
Yes, during the entire childhood & 1756 & 14.8 & 35.6 & 49.5 & \\
Yes, during major part & 3069 & 9.2 & 32.9 & 57.8 & \\
Yes, during minor part & 5191 & 5.9 & 27.9 & 66.2 & \\
No & 15,935 & 4.8 & 23.2 & 71.9 & \\
Condescently treated in childhood & & & & & $<.001$ \\
Yes, often & 1980 & 16.7 & 32.2 & 51.1 & \\
Yes, sometimes & 8067 & 6.5 & 28.9 & 64.6 & \\
No & 15,813 & 4.8 & 23.9 & 71.3 & \\
\hline
\end{tabular}

${ }^{*} p$-value based on chi-squared test.

between the childhood circumstances and adult SRH were further attenuated, but remained statistically significant [OR $=1.41$ (95\% CI:1.14-1.76) for economic stress during the entire childhood, OR $=1.33$ (95\% CI:1.11-1.60) for major part of the childhood and OR $=1.99$ (95\% CI:1.612.45) for having often been condescendingly treated in childhood].

\section{Discussion}

The results of this study indicate that both economic stress in childhood and condescending treatment in childhood are associated with SRH in adulthood. The associations were attenuated, but still statistically significant, when adjusted for economic stress and condescending treatment in adulthood and other risk factors for poor SRH. Those who reported economic stress during the entire childhood or during major part of the childhood had an increased risk for poor SRH. In addition, those who were most often exposed to condescending treatment had the highest risk of poor SRH.

The associations between current economic stress or recent exposure to condescending treatment and adult SRH were stronger than the associations between childhood circumstances and adult SRH. Previous studies have shown that current economic difficulties $[12,32,33]$ and recent condescending treatment [17] are strongly associated with poor SRH among adults. Also, the result that childhood economic stress was independently associated with poor SRH is in line with results from previous studies $[11,13]$. We are not aware of previous studies examining the health impacts of being condescendingly treated in childhood, but studies have shown that severe emotional stress in childhood, which might be a result of condescending treatment, can permanently increase the susceptibility to ill health $[34,35]$. Previous studies have also shown that exposure to bullying at school is associated with poor health in adulthood [15, 23-25].

Theories aiming at explaining how early life conditions affect health suggest that the impact is amplified by several parallel mechanisms [1], and that these are operating in complex interaction processes [3]. In the current study, we investigated how two different types of childhood circumstances independently contribute to explain adult health status. Since there was a moderate correlation between economic stress and condescending treatment in childhood these factors were adjusted for each other in all logistic regression models. We also showed that some of the contributions were mediated by adult circumstances and other risk factors, e.g. related to health behaviour [1]. These findings emphasize the importance of the life course perspective, defined as "the long term effects on later health or disease risk of physical or social exposures during gestation, childhood, adolescence, young adulthood and later adult life" [5]. In addition, childhood circumstances have been shown to contribute substantially to health inequalities between people of different educational levels [36]. In young adulthood, a large part of this contribution seems to be explained by behavioural factors and only a minor part by current circumstances [36].

Socioeconomic factors were associated with economic stress and condescending treatment during childhood. Childhood economic stress was more common among persons with low educational level, those born outside Sweden, the unemployed and those on disability pension. Similar results for country of birth and employment have been reported from the southern part of Sweden (Skåne) [13]. Condescending treatment in childhood was most common among the unemployed and those on disability pension. In the final model, where the results were adjusted for socioeconomic factors, the odds ratios were attenuated, indicating that part of the associations between childhood conditions, in particular economic stress, and adult SRH are mediated by adult socioeconomic status such as educational level and employment.

There were small differences in the prevalence of childhood economic stress by age, even though the prosperity level of the country differed remarkably between 
Table 3 Odds ratios for poor and fair self-rated health in relation to condescending treatment in childhood and economic stress in childhood, 25-84 years

\begin{tabular}{|c|c|c|c|c|}
\hline \multirow{2}{*}{\multicolumn{2}{|c|}{ Self-rated health (reference category = good) }} & \multirow{2}{*}{$\begin{array}{l}\text { Model } 1 \\
\text { OR (95\% Cl) }\end{array}$} & \multirow{2}{*}{$\begin{array}{l}\text { Model } 2 \\
\text { OR }(95 \% \text { Cl) }\end{array}$} & \multirow{2}{*}{$\begin{array}{l}\text { Model } 3 \\
\text { OR (95\% Cl) }\end{array}$} \\
\hline & & & & \\
\hline Poor & Economic stress in childhood svårigheter under uppväxten & & & \\
\hline \multirow[t]{16}{*}{$(n=1610)$} & Yes, during the entire childhood & $2.73(2.29-3.25)$ & $2.17(1.81-2.59)$ & $1.41(1.14-1.76)$ \\
\hline & Yes, during major part of the childhood & $1.83(1.57-2.13)$ & $1.59(1.36-1.87)$ & $1.33(1.11-1.60)$ \\
\hline & Yes, during minor part of the childhood & $1.20(1.04-1.38)$ & $1.11(0.96-1.28)$ & $1.02(0.86-1.20)$ \\
\hline & No & Ref & Ref & Ref \\
\hline & Condescently treated in childhood & & & \\
\hline & Yes, often & $4.20(3.57-4.94)$ & $2.60(2.18-3.10)$ & $1.99(1.61-2.45)$ \\
\hline & Yes, sometimes & $1.43(1.27-1.62)$ & $1.23(1.08-1.39)$ & $1.27(1.10-1.47)$ \\
\hline & No & Ref & Ref & Ref \\
\hline & Economic stress past 12 months & & & \\
\hline & Yes, several times & & $5.54(4.74-6.48)$ & $2.57(2.11-3.13)$ \\
\hline & Yes, once & & $3.07(2.51-3.76)$ & $2.01(1.57-2.57)$ \\
\hline & No & & Ref & Ref \\
\hline & Condescently treated during the last 3 months & & & \\
\hline & Yes, several times & & $4.40(3.54-5.47)$ & $3.27(2.50-4.28)$ \\
\hline & Yes, occasionally & & $1.81(1.59-2.06)$ & $1.92(1.65-2.24)$ \\
\hline & No & & Ref & Ref \\
\hline Fair & Economic stress in childhood svårigheter under uppväxten & & & \\
\hline \multirow[t]{16}{*}{$(n=6753)$} & Yes, during the entire childhood & $1.71(1.52-1.92)$ & $1.55(1.38-1.75)$ & $1.33(1.16-1.52)$ \\
\hline & Yes, during major part of the childhood & $1.50(1.37-1.64)$ & $1.40(1.28-1.54)$ & $1.29(1.16-1.42)$ \\
\hline & Yes, during minor part of the childhood & $1.23(1.14-1.33)$ & $1.18(1.09-1.27)$ & $1.13(1.04-1.22)$ \\
\hline & No & Ref & Ref & Ref \\
\hline & Condescently treated in childhood & & & \\
\hline & Yes, often & $2.09(1.86-2.34)$ & $1.65(1.46-1.86)$ & $1.41(1.24-1.61)$ \\
\hline & Yes, sometimes & $1.39(1.31-1.49)$ & $1.28(1.19-1.36)$ & $1.28(1.19-1.38)$ \\
\hline & No & Ref & Ref & Ref \\
\hline & Economic stress past 12 months & & & \\
\hline & Yes, several times & & $2.43(2.16-2.73)$ & $1.64(1.44-1.88)$ \\
\hline & Yes, once & & $1.74(1.52-1.99)$ & $1.49(1.29-1.74)$ \\
\hline & No & & Ref & Ref \\
\hline & Condescently treated during the last 3 months & & & \\
\hline & Yes, several times & & $1.98(1.67-2.36)$ & $1.76(1.46-2.13)$ \\
\hline & Yes, occasionally & & $1.53(1.42-1.65)$ & $1.58(1.45-1.71)$ \\
\hline & No & & Ref & Ref \\
\hline
\end{tabular}

Model 1: Adjusted for sex and age $(n=25,860)$

Model 2: Adjusted for sex, age, economic stress in adulthood and condescending treatment in adulthood $(n=25,662)$

Model 3: Adjusted for sex, age, economic stress in adulthood, condescending treatment in adulthood, employment status, educational level, country of birth, social support, burdensome domestic work, daily smoking, risk consumption of alcohol and physical activity $(n=23,869)$

the interwar period, when the oldest respondents grew up, and the second half of the twentieth century. This may reflect the fact that people interpret economic stress in relative terms, i.e. measured by their income rank in comparison to others rather than being below any specific absolute level of income [37]. A lower response rate in the younger age groups may also have played a role. However, reporting of condescending treatment in childhood differed between age groups. The younger age groups reported higher levels of 
condescending treatment in childhood. This may be due to real differences in exposure between age groups, due to different interpretations of the term "condescending treatment" in different generations or maybe an indication that memories of condescending treatment fade with time. However, a higher prevalence of bullying at school among younger adults (18-29 years) than among those 30-39 years of age has also been reported from a representative population study in Finland [23].

Both economic stress in childhood and condescending treatment, e.g. in school or at home, during childhood were relatively common in this adult general population, about four in ten reported these childhood circumstances. As both these factors were independently associated with adult SRH, public health measures addressed to both material and psychosocial circumstances in childhood are needed to promote the future health in the population. The prevalence of self-reported economic stress during the major part of the childhood, shown to be a particular risk factor for poor SRH in adulthood, was about $17 \%$. This is somewhat higher than the current Swedish childhood poverty rate of $12 \%$, based on register information [28]. Nevertheless, our findings are in line with the notion that childhood poverty of today may have long-lasting negative consequences for health in the general population.

\section{Strengths and limitations}

Conducting retrospective measurements by asking the respondent to report factors in childhood can lead to increased uncertainty compared to longitudinal studies, where all data are collected at the time of exposure. We presume, however, that both childhood economic stress and childhood condescending treatment are such significant experiences that the memories of those are likely to prevail into adulthood, especially if the experiences influenced a large part of the childhood. Moreover, also most previous studies in this field have been constrained to use retrospective data, as objective, prospective data on childhood circumstances are scarce. An additional risk by asking about circumstances in the past is that memories can be influenced by prevailing conditions at the time of reporting, i.e. the so-called recall bias. For instance, if the respondent is experiencing hard current life conditions, it is more likely that memories of difficulties in childhood come into mind [38]. However, in the present study almost half of those, who reported condescending treatment in childhood, reported no condescending treatment during the past 3 months, suggesting that recall bias was not a major problem. In addition, a previous evaluation of the method of examining childhood economic stress retrospectively reported good validity [39].
A further limitation of the study is that both the risk factors and the outcome were self-reported and that the validity of the risk factor measures is uncertain. However, experiences of discrimination are usually measured through self-reports and different studies have used different measures of perceived discrimination since there is a lack of validated instruments to be used in large scale epidemiologic studies $[21,22]$. Furthermore, previous studies on childhood circumstances and adult health have based their results on self-reported data, with dichotomous measures or measures with a few categories, on economic stress in childhood [12, 13, 23] and for example on bullying at school $[23,24,36]$.

The response rate in the study was $53 \%$. Non-response is more common in groups that are economically disadvantaged, such as persons with low educational level and those born outside the Nordic countries [40]. It is therefore possible that the prevalence of childhood economic stress, and perhaps even condescending treatment in childhood, may be underestimated in our study. However, it is unlikely that non-response would have explained the associations found between childhood circumstances and SRH.

A strength of the current study is that we investigated two distinct types of childhood conditions, one material and one psychosocial, simultaneously. A further strength is that the study was based on a representative sample of the adult population in a large area in Sweden with a similar distribution of SRH as in the nationally representative sample in Sweden [31]. The study includes different types of municipalities and residential areas as well as different socioeconomic conditions. The sample covers a wide age range, from young adults to old-age pensioners, with varying childhood conditions. An additional strength is the use of SRH as health outcome, as it is a wellknown and validated measurement [41].

\section{Conclusion}

To our knowledge, this is the first population based study in Sweden to show that both economic stress in childhood and condescending treatment in childhood are relatively common in the general population and that they are associated with SRH in adulthood, even when adjusted for current circumstances and other risk factors. The results underline the importance of taking into account both material and psychosocial circumstances over the whole life course when developing public health measures. Thus, efforts to reduce childhood poverty and to promote good psychosocial conditions in childhood should have positive long-lasting beneficial effects on public health. 


\section{Additional file}

Additional file 1: Life and health long questionnaire 2012.pdf; Survey questionnaire 2012. (PDF $140 \mathrm{~kb}$ )

\section{Abbreviation}

SRH: Self-rated health

\section{Acknowledgement}

Not applicable

\section{Funding}

The survey was funded by the County Councils of Sörmland, Västmanland (now Region Västmanland), Uppsala and Örebro. The county councils did not affect the content of the study.

\section{Availability of data and materials}

The datasets analysed during the current study are not publicly available due to confidentiality and regulations under the Swedish law (the law of official statistics (2001:99 6§) and the law of secrecy (1980:100 9 chap. 4§)).

\section{Authors' contributions}

FG, HGE and AM designed the study and interpreted the results. FG drafted the manuscript, HGE conducted the statistical analyses. AM critically revised the manuscript for intellectual content. All authors contributed to writing and revising the manuscript. All authors read and approved the final version of the manuscript.

\section{Competing interests}

The authors declare that they have no competing interests.

\section{Consent for publication}

Not applicable.

\section{Ethics approval and consent to participate}

The survey was approved by the Regional Board of Ethics, Uppsala (EPN 2012/256). The respondents gave their informed consent to participate by answering the questionnaire.

\section{Publisher's Note}

Springer Nature remains neutral with regard to jurisdictional claims in published maps and institutional affiliations.

\section{Author details}

${ }^{1}$ Centre for Clinical Research Sörmland, Uppsala University, Eskilstuna, Sweden. ${ }^{2}$ Division of Community Medicine, Department of Medical and Health Sciences, Linköping University, Linköping, Sweden. ${ }^{3}$ Competence Centre for Health, Region Västmanland, 72189 Västerås, Sweden.

${ }^{4}$ Department of Public Health, Karlstad University, Karlstad, Sweden.

Received: 21 October 2016 Accepted: 15 May 2017

Published online: 22 May 2017

\section{References}

1. Graham H, Power C. Childhood disadvantage and adult health: a lifecourse framework. London: Health Development Agency; 2004.

2. Boyce WT, Keating DP. Should we intervene to improve childhood circumstances? In: Kuh D, Ben-Shlomo Y, editors. A life course approach to chronic disease epidemiology. 2nd ed. Oxford New York: Oxford University Press; 2004. p. 414-45.

3. Wadsworth M, Butterworth S. Early life. In: Marmot M, Wilkinson RG, editors. Social determinants of health. 2nd ed. Oxford New York: Oxford University Press; 2006. p. 31-53.

4. Shonkoff JP, Phillips DA. From neurons to neighborhoods, The science of early childhood development. Washington DC: National Academy Press; 2000.

5. Kuh D, Ben-Shlomo Y, Lynch J, Hallqvist J, Power C. Glossary: life course epidemiology. J Epidemiol Community Health. 2003;57:778-83.
6. Ford ES, Anda RF, Edwards VJ, Perry GS, Zhao G, Li C, et al. Adverse childhood experiences and smoking status in five states. Prev Med. 2011;53:188-93.

7. Dube SR, Anda RF, Felitti VJ, Edwards VJ, Croft JB. Adverse childhood experiences and personal alcohol abuse as an adult. Addict Behav. 2002;27:713-25

8. Graham H. Unequal lives - health and socioeconomic inequalities. Maidenhead: Open University Press; 2007

9. Blane D. The life course, the social gradient, and health. In: Marmot M, Wilkinson RG, editors. Social determinants of health. 2nd ed. Oxford New York: Oxford University Press; 2006. p. 54-77.

10. Huurre T, Aro H, Rahkonen O. Well-being and health behaviour by parental socioeconomic status: a follow-up study of adolescents aged 16 until age 32 years. Soc Psychiatry Psychiatr Epidemiol. 2003;38:249-55.

11. Poulton R, Caspi A, Milne BJ, et al. Association between children's experience of socioeconomic disadvantage and adult health: a life-course study. Lancet. 2002:32:1640-5.

12. Laaksonen M, Rahkonen O, Martikainen P, Lahelma E. Socioeconomic position and self-rated health: the contribution of childhood socioeconomic circumstances, adult socioeconomic status, and material resources. Am J Public Health. 2005;95:1403-9.

13. Lindström M, Hansen K, Rosvall M. Economic stress in childhood and adulthood, and self-rated health: a population based study concerning risk accumulation, critical period and social mobility. BMC Public Health. 2012;12:761.

14. Laaksonen $\mathrm{E}$, Martikainen $\mathrm{P}$, Lahelma $\mathrm{E}$, et al. Socioeconomic circumstances and common mental disorders among Finnish and British public sector employees: evidence from the Helsinki health study and the Whitehall II study. Int J Epidemiol. 2007;36:776-86.

15. Pirkola S, Isometsä E, Aro H, et al. Childhood adversities as risk factors for adult mental disorders. Results from the health 2000 study. Soc Psychiatry Psychiatr Epidemiol. 2005;40:769-77.

16. Pudrovska T, Schieman S, Pearlin LI, Nguyen K. The sense of mastery as a mediator and moderator in the association between economic hardship and health in late life. J Aging Health. 2005;17:634-60.

17. Molarius A, Berglund K, Eriksson C, et al. Socioeconomic conditions, lifestyle factors and self-rated health among men and women in Sweden. Eur J Pub Health. 2007:17:125-33.

18. Ahnquist J, Wamala S. Economic hardship in adulthood and mental health in Sweden. The Swedish National Public Health Survey 2009. BMC Public Health. 2011:11:788.

19. Molarius A, Berglund K, Eriksson C, et al. Mental health symptoms in relation to socio-economic conditions and lifestyle factors - a population-based study in Sweden. BMC Public Health. 2009;9:302.

20. Lahelma E, Lallukka T, Laaksonen M, Saastamoinen P, Rahkonen O. Workplace bullying and common mental disorders: a follow-up study. J Epidemiol Community Health. 2012;66:e3.

21. Krieger N. Discrimination and health. In: Berkman LF, Kawachi I, editors. Social Epidemiology. Oxford: Oxford University Press; 2000. p. 36-75.

22. Pascoe EA, Smart RL. Perceived discrimination and health: a meta-analytic review. Psychol Bull. 2009:135:531-54.

23. Kestilä L, Koskinen S, Martelin T, Rahkonen O, Pensola T, Aro H, et al. Determinants of health in early adulthood: what is the role of parental education, childhood adversities and own education? Eur J Pub Health. 2006:16:306-15.

24. Lund R, Nielsen KK, Hansen DH, et al. Exposure to bullying at school and depression in adulthood: a study of Danish men born in 1953. Eur J Pub Health. 2009:19:111-6.

25. Sigurdson JF, Undheim AM, Wallander JL, Lydersen S, Sund AM. The longterm effects of being bullied or a bully in adolescence on externalizing and internalizing mental health problems in adulthood. Child Adolesc Psychiatry Ment Health. 2015:9:42.

26. Smith PK, Singer $\mathrm{M}$, Hoel H, Cooper CL. Victimization in the school and the workplace: are there any links? Br J Psychol. 2003:94:175-88.

27. Elstad Jl. Childhood adversities and health variations among middleaged men: a retrospective lifecourse study. Eur J Pub Health. 2005; 15:51-8

28. Salonen T. Barnfattigdom i Sverige: årsrapport 2013. [child poverty in Sweden: annual report 2013.]. Stockholm: Rädda barnen; 2013.

29. Hjern A. Children's health: health in Sweden: the National Public Health Report 2012. Chapter 2. Scand J Public Health. 2012;40(Suppl 9):23-41. 
30. Babor TF, de la Fuente JR, Saunders J, Grant M. AUDIT The alcohol use disorder identification test. World Health Organization. WHO/PSA/92.4. 1992.

31. The Public Health Agency of Sweden. Hälsa på lika villkor? Nationella folkhälsoenkäten. [Health on equal terms? The national public health survey.] 2016. http://www.folkhalsomyndigheten.se. Accessed 6 Dec 2016.

32. Ahnquist J, Fredlund P, Wamala SP. Is cumulative exposure to economic hardships more hazardous to women's health than men's? A 16-year follow-up study of the Swedish survey of living conditions. J Epidemiol Community Health. 2007;61:331-6.

33. Tucker-Seeley RD, Harley AE, Stoddard AM, Sorensen GG. Financial hardship and self-rated health among low-income housing residents. Health Educ Behav. 2013;40:442-8.

34. Wadsworth MEJ. Delinquency, pulse rates and early emotional deprivation. Brit J Criminol. 1976;16:245-56.

35. Surtees P, Wainwright N, Day N, Brayne C, Luben R, Khaw KT. Adverse experiences in childhood as a developmental risk factor altered immune status in adulthood. Int J Behav Med. 2003;10:251-68.

36. Kestilä L, Martelin T, Rahkonen O, Härkänen T, Koskinen S. The contribution of childhood circumstances, current circumstances and health behaviour to educational health differences in early adulthood. BMC Public Health. 2009;9:164.

37. Boyce CJ, Brown GD, Moore SC. Money and happiness: rank of income, not income, affects life satisfaction. Psychol Sci. 2010;21:471-5.

38. Bartley M. Health inequality, an introduction to theories, concepts and methods. Cambridge: Polity press; 2004.

39. Mackenbach JP, van de Mheen H, Stronks K. A prospective cohort study investigating the explanation of socio-economic inequalities in health in the Netherlands. Soc Sci Med. 1994;38:299-308.

40. Lindén-Boström M, Persson C. A selective follow-up study on a public health survey. Eur J Pub Health. 2013;23:152-7.

41. Idler EL, Benyamini Y. Self-rated health and mortality: a review of twentyseven community studies. J Health Soc Behav. 1997;38:21-37.

\section{Submit your next manuscript to BioMed Central and we will help you at every step:}

- We accept pre-submission inquiries

- Our selector tool helps you to find the most relevant journal

- We provide round the clock customer support

- Convenient online submission

- Thorough peer review

- Inclusion in PubMed and all major indexing services

- Maximum visibility for your research

Submit your manuscript at www biomedcentral.com/submit 